\title{
Research on the Influence of Reference Group Types on Consumers' Purchase Decisions from the Perspective of Social Networks
}

\author{
Hong Jin ${ }^{1}$ \\ Guanghua School of Management, Peking University \\ School of Business, Jiangxi Normal University \\ Beijing, China \\ 342944219@qq.com
}

\author{
Yunting $\mathrm{Miao}^{2}$ \\ School of Business \\ Jiangxi Normal University \\ Jiangxi, China \\ 771022025@qq.com
}

\begin{abstract}
After years of research, foreign scholars have confirmed that the reference group has a significant impact on consumers' purchase decisions and brand preferences. In recent years, some scholars have considered that due to the impact of traditional culture, domestic consumers are more subtle in their expressions than Western consumers who pursue individuality. China has a close human relationship and a high degree of socialization. What's more, consumers have a stronger mindset. Therefore, the influence of reference groups in the Chinese market environment is greater than that of Western societies. The research on the influence of reference groups in the context of Chinese social networks is of great importance and particularity, but domestic research is obviously insufficient. This paper examines domestic and foreign research on reference groups and consumer online shopping decisions. From the perspective of social networks, this paper discusses the impact of two reference group types on consumer purchasing decisionmaking among the member groups and non-member groups including aspiration reference groups, dissociative reference groups, and neutral reference groups. In subsequent studies, empirical methods will be used to further verify the impact of reference groups on purchase decisions. Reference groups play an important role in practice, and companies should pay more attention to reference groups when developing marketing strategies.
\end{abstract}

Keywords-Social networks; Member groups; Non-member groups; Consumers' purchase decisions

\section{INTRODUCTION}

With the development of Internet technology, Facebook, Instagram, Twitter (a popular social software in the United States), kakao talk (the most popular social software in Korea), Line (the most popular social software in Japan), GaGa (A global multilingual translation of social software), as well as WeChat, Weibo and QQ, have mushroomed. Users create their own accounts and establish friendships with other users, and then use social networks for daily communication. With the improvement of network communication technology, the popularity of smart phones, the rise of the mobile Internet, various social softwares have also begun to focus on mobile development. Social networks have clearly become an integral part of most users' lives. Since individuals live in the collective, social groups' values, behavioral norms, and relationship quality influence consumers' consumption decisions all the time, which makes it impossible to ignore the important role of the group in the process of researching consumer purchase decision-making behavior.

The impact of reference groups on consumer purchasing decisions is particularly significant, which has attracted widespread attention from the industry and academia. Scholars in the fields of sociology, psychology, and consumer behavior researched the reference groups. Many studies have found that the reference group has an impact on consumers' attitudes and behaviors. On the one hand, the reference group can provide consumers a lot of information and provide a reference for consumers' decision-making. On the other hand, because the individual has social characteristics, the behavior that consumers make consistent with the reference group is the way consumers express their self identity and get group recognition. After decades of research, foreign scholars have studied the concepts, dimensions, influencing factors, mechanisms, and effects of reference groups. However, in China, which advocates collectivism, the influence of the reference group is undoubtedly more pronounced than the western countries that prevail in individualism. At present, some domestic scholars have studied the influence of reference groups on consumer brand attitudes and behaviors. However, the impact of the type of reference group on consumer purchasing decisions in different contexts has not been thoroughly discussed by scholars.

Based on this, this paper attempts to explore the impact of reference groups on the consumer purchasing decision in the social network and provides practical inspiration for the enterprise information dissemination. 


\section{LITERATURE REVIEW}

\section{A. Social Networks}

Social networks are relatively stable systems composed of social relationships between certain individuals. With the development of social networks, social networks have pointed not only to relationships between individuals, but also to the relationships of groups or organizations, such as families and departments. Corporate information can be disseminated among network members through social networks. Network members can also obtain resources such as knowledge and information through social networks. Social networks include real social networks and virtual social networks.

In real life, communication with others is the main behavior of individuals, and people always connect with each other to form a social network. There are two well-known theories in the real social network: Six Degree of Separation and Three Degrees of Influence Rule. Six Degree of Separation holds that in any real world, any two people who are not known can connect with each other through six people. This shows that there is a widespread "weak ties" in society, which makes people close to each other through weak bonds. The Three Degrees of Influence Rule means that our actions, attitudes, and emotions will ripple in our social network, affect our friends (once), and our friends' friends (second degree). Friends of our friend's friends (three degrees). If it exceeds three degrees, the influence will gradually disappear. There are strong connections between people within three degrees of each other, and strong connections can cause behavior.

Virtual social networks are the extension of human relationships in real social networks. The wide application of mobile social software closely links real social networks to virtual social networks, which allows groups in social networks to have the opportunity to exchange product information, experiences, services, and so on. Through the Internet, people can construct personal social relationships. Virtual social networks play a huge role in people's real life. Virtual social networks have a positive impact on the expansion of real social networks, capital accumulation, and information dissemination. The mobile social media as the main body of the virtual social network construction, in addition to basic social functions, also provides users with massive information consulting and knowledge sharing capabilities. Structural holes are networked social systems that are extended out of the Internet economy to redefine human relationships. Structural holes refer to nonrepeated relationships between two related people.

\section{B. Reference Groups}

Reference groups have important influence on consumer behavior and are an important factor influencing consumer decision making. Scholars have different definitions of reference groups. For example: Park and Lessig (1997) believe that reference groups are individuals or groups from reality or imagination that have a significant impact on individual evaluations, wishes, expectations, or behaviors. Du Weiqiang, et al. (2009) the definition of reference group is an important social group used by consumers to compare themselves. There are many famous scholars who have studied the reference groups. It is widely recognized that Park and Lessig (1977), on the basis of their predecessors, divided the reference groups into informational influences, utilitarian influences, and valueexpressive influences. Turner (1991) divides the reference group into member groups and non-member groups. Nonmember groups include aspiration reference groups, dissociative reference groups, neutral reference groups.

The consumer's own attitudes and perceptions play a leading role in consumer decision-making, but the reference group influences consumer behavior to a large extent. Especially in the context of the Chinese market, consumers are more socialized and interpersonal relationships are closer, and reference groups have greater impact on consumer behavior. In recent years, with the increasing development of social networking applications, celebrities, idols, and other reference groups have greatly influenced people's buying decisions. In addition, the complexity of network information and the fragmentation of information make consumers spend a lot of time and energy searching for information. Based on the principle of consumption that has limited cognitive resources and minimized costs, people's dependence on reference groups will also increase. Current studies on reference groups focus on the impact of reference groups on consumer attitudes and purchasing behavior, but studies of reference groups are few in different contexts.

\section{Consumer Purchase Decisions}

Consumer purchase decision refers to the process of choosing and buying a product that can meet a particular need (Yunhang Cheng, Yicai Li, Gongyu Shi, 2010). There are a lot of researches on the process of consumer purchase decision. Haubl and Trifts (2000) believes that consumers will experience two stages in the process of online shopping. They tend to look at a large number of commodity information and make a preliminary screening, and then compare the selected information to make a purchase decision. Chen and Chang (2003) propose a model of consumer online purchase decision. Jinli Sun (2011) established a dynamic model of consumer decision-making behavior in online shopping, and analyzed the factors that affect the decision-making process of consumers.

The research on the influencing factors of online consumer purchase decision-making scholars are mostly divided into individual factors from consumers and factors from the external environment. Individual factors can be further divided into stable factors, random factors, and psychological factors. Stability factors refer to the individual's age, gender, income, education, and occupation. Random factors refer to the situation conditions consumers face when purchasing, such as the style of shop decoration, product placement, and so on. Psychological factors include consumer perceptions, attitudes and motivations. The individual factors of consumers are mainly focused on perceived risks, attitudes, emotions, and privacy. External environmental factors include social and cultural influences and corporate factors. Social and cultural factors mainly refer to two aspects: interpersonal relationship and social value orientation. Corporate factors mainly refer to brands, prices, and product characteristics. The theoretical research on consumer purchasing decision has been increasingly perfected, so the focus of scholars' research has shifted from qualitative analysis to quantitative analysis. 
At present, most of the domestic and foreign research on consumer purchase decision is focused on the influencing factors of consumer purchase decision and the process of purchasing decision, and the related research on consumer purchase decision is less based on the social network perspective. Based on this, this study will examine the influence of member groups and non-member groups on consumer purchasing decisions from the perspective of social networks.

\section{RESEARCH MODEL}

For consumers, they can obtain information about products, companies, spokespersons, etc. from the group, which has a certain degree of promotion or inhibition on the consumer's purchase decision. Therefore, based on the perspective of social networks, this study discusses the impact of member groups and non-member groups (aspiration reference groups、 dissociative reference groups neutral reference groups) on consumer purchasing decision-making .

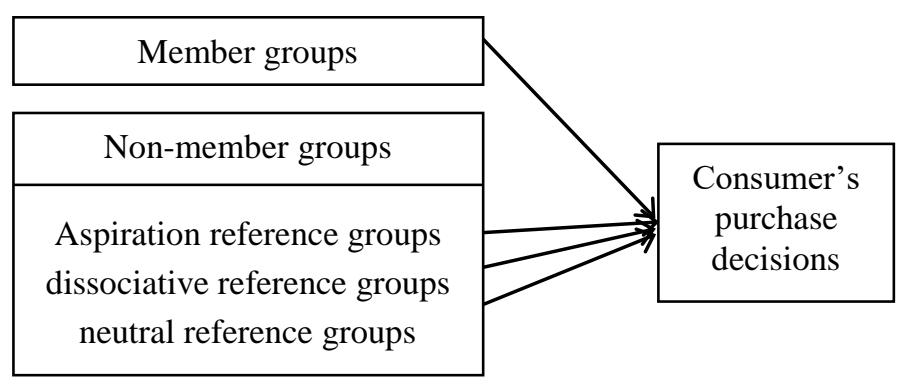

Fig. 1 The Impact of Reference Groups on Consumer's Purchase Decisions

\section{RESEARCH ASSUMPTION}

Reference groups includes two dimensions: member groups and non-member groups. Non-member groups include aspiration reference groups, dissociative reference groups and neutral reference groups. Based on the theory of social influence, this study discusses the influence of member groups, aspiration reference groups, dissociative reference groups and neutral reference groups on consumer purchasing decisions.

\section{A. The Influence of Member Groups on Consumer's Purchase Decisions}

People can gain a sense of identity from the group. People tend to use brands whose image is consistent with the identity of their members (Childers \& Rao, 1992). Person with strong ability in the group establish prestige through information sharing and gain the higher status. Close membership makes the behaviors and opinions of members in the group more valuable. Member groups influence Consumer purchase intention (Terry \& Hogg, 1996) and brand attitude (Haslam et al., 1996). Participants provided more common information that favored their initial choice and provided less private information that was detrimental to their initial choice (Dianshan Deng, 2005). The degree of consumer's brand recognition under the influence of member groups is higher than the degree of consumer's brand identity under the influence of circumvention group (Ketai Ma, 2013). The following assumptions:

H1: Member reference groups have positively effect on consumer purchase decisions.

\section{B. The influence of aspiration reference groups on consumer's purchase decisions}

Aspiration reference groups are non-member groups that consumers want to become members of. The individual establishes a connection with the group by mimicking the behavior of member group he aspires to, in order to use the group's image to express and enhance the self-image. Second, group members are psychologically subordinate to the needs of a certain group. Consumers can respond positively to the group by making consistent consumer decisions with the group. The craving for groups can motivate people's Purchasing motivation (Lockwood \& Kunda, 1997). Consumers will buy products that the brand image is consistent with aspiration reference groups, to indicate what type of person they are (Weiqiang Du, Chunling Yu, Ping Zhao, 2009). The following assumptions:

H2: Aspiration reference groups have positively effect on consumer purchase decisions.

\section{The influence of dissociative reference groups on consumer purchase decisions}

Dissociative reference groups are non-member groups that consumers want to completely delimit. Evasion groups are non-member groups that consumers want to completely delimit. Consumers with stronger face awareness are more concerned with the opinions of others than those with weak face. They also pay more attention to the social attributes and symbolic attributes of products. When the brand image is consistent with the circumvention group, consumers who fear the loss of face awareness will show a strong brand change intention (Li Wei, 2011). Businesses should avoid as far as possible the circumvention of the group's negative impact on consumers. When consumers have identified with the brand and circumvented the group's disapproval, avoiding groups can increase consumers' brand recognition (Mark, 2013). The following assumptions:

H3: Dissociative reference groups have adversely effect on consumer purchase decisions.

\section{The influence of neutral reference groups on consumer purchase decisions}

Neutral groups refer to consumers who do not belong to a certain group, are neither eager to become members of the group nor do they feel bound to draw a line with the group. Loose relations will show different characteristics in different situations. Consumers who rely on self-construction will reduce their brand attitude when they see a neutral group, while consumers who have self-constructed will not change their brand attitude when they see a neutral group (Hongyan Liu, Wei Wei, 2014). The following assumptions:

H4: Neutral reference groups have little effect on consumer purchase decisions. 


\section{Research Methodology}

\section{A. Literature Research Method}

This study reviews, collates, and summarizes relevant literature about social networks, reference groups and consumer purchasing decisions. On the basis of previous studies, combining the characteristics of social networks, we tried to construct a model of the impact of reference groups on consumer purchasing decisions and put forward research hypotheses.

\section{B. Empirical Research Method}

The latter part of this study will use empirical research methods to collect the required data through questionnaire surveys. SPSS21.0 software and AMOS21.0 software will be used to test the reliability and validity of the collected questionnaire data to ensure the authenticity and comprehensiveness of the data obtained. The research process will strictly control the data in order to verify the model and assumptions.

\section{CONCLUSION}

When referring to an individual's social relations, individuals always unconsciously place themselves in groups in order to gain more recognition. Everyone in the group has the dual status of helper and Beneficiary. At present, the research on the impact of reference groups on consumer purchasing decisions is dominated by foreign scholars. Only some scholars in China have studied the purchase decision of a specific reference group. Obviously, these studies are not enough. The research on impact of the reference group type on consumer purchasing decisions is not only a theoretical supplement to social networks, reference groups, and consumer purchasing decisions, but also provides inspirations to the company's customer relationship management. Enterprises adopt "reference groups $\rightarrow$ consumers" information dissemination method is better than "advertisement $\rightarrow$ consumers". This kind of information transfer can increase consumer awareness of corporate products and brands and can also promote the reputation of corporate products and brands. In social networks, companies should focus on word of mouth marketing rather than advertising.

There are three limitations in the study. First, this article does not delve deeper into the motivation of the reference group to the consumer purchase decision path. Second, this study only confirmed the impact of reference groups on consumer purchasing decisions from a theoretical perspective and has not been empirically tested. Third, the paper does not compare the two dimensions of the social network's real social network and virtual social network. In different situations, the impact of the reference group on consumers' purchase decision may be different. Therefore, in the follow-up studies, empirical tests can be used to test whether the above theories are valid, and relevant mediation variables and adjustment variables can also be added for further discussion.

\section{ACKNOWLEDGEMENT}

This study is supported by the National Natural Science Foundation of China (No.71562020) and the China Postdoctoral Science Foundation (No.2017M620532).

\section{REFERENCES}

[1] Childers, Terry L., and A. R. Rao. "The Influence of Familial and Peerbased Reference Groups on Consumer Decisions." Journal of Consumer Research 19.2(1992):198-211.

[2] Terry, Deborah J., and M. A. Hogg. "Group Norms and the AttitudeBehavior Relationship: A Role for Group Identification." Personality \& Social Psychology Bulletin 22.8(1996):776-793.

[3] Haslam, S. Alexander, et al. "Stereotyping and social influence: The mediation of stereotype applicability and sharedness by the views of ingroup and out-group members." British Journal of Social Psychology 35.3(1996):369-397.

[4] Dianshan Deng. The influence of group members' information sharing on group decision-making. Peking University 2005.

[5] Ketai Ma. "A Study of the Effects of Member Groups and Evasion Groups on Consumers' Brand Identity". JMS China Marketing Science Academic Conference and Ph.D. Student Forum 2013.

[6] Lockwood, Penelope, and Z. Kunda. "Superstars and me: Predicting the impact of role models on the self." Journal of Personality \& Social Psychology 73.1(1997):91-103.

[7] Weiqiang Du, Chunling Yu and Ping Zhao. "Reference group type and self-brand contact". Journal of Psychiatry 41.2 (2009):156-166. (In Chinese)

[8] Hongyan Liu and Wei Wei. "The influence of non target consumer brand behavior on the brand attitude of target consumers." China Marketing Science Academic Conference 2014. (In Chinese)

[9] Park, C. Whan, and V. P. Lessig. "Students and Housewives: Differences in Susceptibility to Reference Group Influence." Journal of Consumer Research 4.2(1977):102-110.

[10] Moutinho, Luiz. "Cultural Influences and Reference Groups." European Journal of Marketing 21.10 (1987): 7-9. Print.

[11] Turner, James R, S. G. Hosking, and J. W. Livingston. "Microprocessor controlled liquid chemical delivery system and method." US, US5014211. 1991.

[12] Yunhhang Cheng, Yicai Li, Gongyu Shi. Marketing. Chemical Industry Press, 2010.(In Chinese)

[13] Haubl, Gerald, and Valerie Trifts. "Consumer Decision Making Decision Aids in Online Effects of Shopping the Environments." Marketing Science 19.1 (2000): 4-21. Print.

[14] Chen, Xinyin, L. Chang, and Yunfeng He. "The Peer Group as a Context: Mediating and Moderating Effects on Relations between Academic Achievement and Social Functioning in Chinese Children." Child Development 74.3(2003):710-727. (In Chinese)

[15] Jingli Sun. "Construction of consumer decision behavior model in online shopping." China Management Informationization 18(2011):101-103. (In Chinese) 